\title{
An Investigation on Radiation Shielding Properties of Borosilicate Glass Systems
}

\author{
Duygu Sen BAYKAL ${ }^{1 *}$, Huseyin Ozan TEKIN ${ }^{2}$, R. Burcu CAKIRLI ${ }^{3}$ \\ ${ }^{1}$ Istanbul University, Institute of Graduate Studies in Science and Engineering, Dep. of Physics, Istanbul-Turkey. \\ * Corresponding Author : duygu.sen@ ogr.iu.edu.tr ORCID: 0000-0001-9833-9392 \\ ${ }^{2}$ Sharjah University, Department of Medical Diagnostic Imaging Program, 27272, United Arab Emirates (UAE). \\ tekin765@gmail.com ORCID:0000-0002-0997-3488
}

${ }^{3}$ Istanbul University, Department of Physics, 34134 Istanbul, Turkey. rburcu@istanbul.edu.tr ORCID: 0000-0002-8400-1718

\section{Article Info:}

DOI: $10.22399 /$ ijcesen.960151

Received : 30 June 2021

Accepted : 31 July 2021

\section{Keywords}

Borosilicate glasses Shielding parameters Buildup factors

Py-MLBUF

\begin{abstract}
:
The aim of this research is to examine the radiation shielding properties of $5 \mathrm{~B}_{2} \mathrm{O}_{3}-40 \mathrm{SiO}_{2}-(55-\mathrm{x}) \mathrm{Al}_{2} \mathrm{O}_{3} \mathrm{xBaO}(\mathrm{BSABa}-\mathrm{x})$ (where $\mathrm{x}=25,28,31$ and, 34) lead-free glass systems, which are containing barium and aluminum oxide added to borosilicate glasses, with varying from 25 to 34 weight fractions. Shielding parameters, such as linear attenuation coefficients (LAC), mass attenuation coefficients (MAC), mean free path (MFP), effective atomic number $\left(Z_{\mathrm{eff}}\right)$, effective electron density $\left(\mathrm{N}_{\text {eff }}\right)$, half-value layer (HVL), tenth-value layer (TVL), effective atomic weight $\left(\mathrm{A}_{\mathrm{eff}}\right)$, exposure buildup factors $(\mathrm{EBF})$ and energy absorption buildup factors (EABF) enable us to obtain information about the radiation shielding power of composite glass material groups. Therefore, the mass attenuation coefficients (MAC), for the 0.015-15 MeV gamma-ray energies are obtained by using the Py-MLBUF online software to determine photon shielding parameters of BSABa-x glass systems. The results are shown that the glass system, which contains higher $\mathrm{BaO}$ concentration has higher mass attenuation coefficients. BSABa-34 glass has the highest MACs, ranging from $0.111 \mathrm{~cm}^{2} / \mathrm{g}$ to $90.400 \mathrm{~cm}^{2} / \mathrm{g}$, while $\mathrm{BSABa}-25$ glass has the lowest values, ranging from $0.099 \mathrm{~cm}^{2} / \mathrm{g}$ to $69.000 \mathrm{~cm}^{2} / \mathrm{g}$. The BSABa-34 glass with the highest $\mathrm{BaO}$ contribution has the thinnest MFP and HVL values. In addition, photon buildup is minimized by adding $\mathrm{BaO}$ to the BSABa-x glasses. Accordingly, we can conclude that adding $\mathrm{BaO}$ to aluminum borosilicate glasses at increasing rates, improves nuclear radiation resistance properties.
\end{abstract}

\section{Introduction}

Radiation obtains benefit when used for diagnosis and treatment within certain dose limitations, but it can also cause to destructive biological effects. In addition to its natural level existing in nature, minimizing the harmful effects of radiation from artificial sources requires maximum protection. Shielding, one of the basic principles of protection, is defined as a material environment which radiation can absorb its energy as a result of the interaction. Radiation protection is provided by the use of materials which's shielding parameters are well known and pre-determined for this material environment. Lead $(\mathrm{Pb})$ is the material that has been widely used since ancient times for radiation protection due to the various advantages provided by its physical and chemical properties. With the developing technology, lead, which has been discovered to be a heavy metal by spectroscopic analysis, has a high density and therefore is in the heavy metals class. Thanks to this feature, it has been discovered that it is the best absorbent material environment when it interacts radiation energy, and it has been used for shielding and it continues to be widely used today [1-7] However, in addition to the advantages of lead, it also has important disadvantages such as the low material 
strength, the difficulties it causes during its use, the cost, the lack of a transparent structure. Due to its widespread use, the structure of lead accumulated in the environment is not suitable for biodegradation, and therefore, with its increasing concentration, it causes a permanent threat to nature and living things by taking place in the environment. Almost all functions in human body can be affected by the toxic effects caused by lead through respiration, skin absorption, and digestion. These disadvantages of lead accelerated the search for materials that can be used as an alternative to traditional materials used for shielding [8-10]. Glass panes are important requirement where radiation is used, especially in nuclear facilities and hospitals. Glass materials used in these compartments must also have strong radiation attenuating features. Today, glass materials are doped with both lead and lighter heavy metals to increase their resistance to radiation. However, since these composite leaded glasses contain both toxic heavy metals and the level of transparency can not be achieved at the desired level. It has become an important need to develop lead-free glass materials that do not harm the environment and people, and also have more transparent structure [11-14]. Developing lead-free protective material is very important for the safe use of radiology rooms. The most important feature of the shielding material is the weakening of gamma photons which have very high ability to penetrate into the substance. This could only be accomplished by using materials that include elements with a high atomic number and hence a high density [15-20]. To determine the feasibility of using any glass sample as a photon shielding material, detailed studies are conducted to determine its physical properties, including linear attenuation coefficients (LAC), mass attenuation coefficients (MAC), mean free path (MFP), effective atomic number $\left(Z_{\text {eff }}\right)$, effective electron density (Neff), half-value layer (HVL), tenth-value layer (TVL), effective atomic weight (Aeff), exposure buildup factors (EBF) and energy absorption buildup factors (EABF). When all of these parameters are established, we may recommend which materials or material classes can provide the best defense. The mass attenuation coefficient $\left(\mu_{m}\right)$ is one of these parameters; it indicates the amount of photons scattered or absorbed by the interacting material. The mass attenuation coefficient is regarded as a fundamental parameter that can be used to calculate additional shielding parameters [19-23]. Additionally, the effective atomic number ( $\left.Z_{\text {eff }}\right)$ is a critical parameter for interpreting the attenuation efficiency of gamma photons by a multi-element substance. $Z_{\text {eff }}$ indicates the protective material's efficiency; a higher $Z_{\text {eff }}$ value indicates that photons are more likely to be absorbed due to the presence of more electrons to communicate with. Additionally, since the mean free path (MFP) is an energy-dependent quantity, it allows the determination of the distance traveled by a photon in a sample prior to any interaction [23-26]. The mass attenuation coefficients (MAC) for 0.015-15 MeV gamma-ray energies are determined using the Py-MLBUF online software in order to determine the photon shielding parameters of the BSABa-x glass systems tested in this analysis. MAC values are used to calculate various shielding parameters for BSABa-x glasses, including the half value layer (HVL), energy buildup and energy absorption buildup factors (EBF and EABF), and mean free path (MFP). The Py-MLBUF software has been used extensively to investigate the photon and neutron shielding properties of glasses [27]. Numerous experiments have been conducted to determine the mass attenuation coefficient for various glass systems, including borosilicate and heavy metal oxide glasses [28-33]. While the majority of these studies analyze the radiation shielding parameters of various glasses at medium and high energy levels, there are very few studies that examine the gamma and neutron radiation shielding parameters of various glass systems at medical diagnostic energies [34-37]. Therefore, this study include radiation shielding parameters of the $5 \mathrm{~B}_{2} \mathrm{O}_{3}$ $40 \mathrm{SiO}_{2}-(55-x) \mathrm{Al}_{2} \mathrm{O}_{3}-x \mathrm{BaO}$ (BSABa-x), (where $\mathrm{x}$ $=25,28,31$ and 34 (with these additive rates theoretical $\rho$ range from 3.798 to $3.957 \mathrm{~g} / \mathrm{cm}^{3}$ )) glass systems, which are containing barium and aluminum oxide added to borosilicate glasses and theoretical density range from 3.798 to $3.957 \mathrm{~g} / \mathrm{cm}^{3}$, in medical diagnosis energy scales.

\section{Materials and Methods 2.1 Shielding Parameters}

As a measure of the absorption of a photon by the material, the linear attenuation coefficients (LAC) of the materials are examined [25]. The LAC, which is a quantity that needs to be investigated in many materials to be effectively protected from radiation, gives the probability of any interaction per unit length of a photon, and it expresses the total probability of occurrence of photoelectric events, Compton scattering, pair formation events. The LAC is expressed as [36-38];

$\mu=\frac{\operatorname{In}\left[I / I_{0}\right]}{t}$ 
(where $\mathrm{I}$ and $\mathrm{I}_{0}$ show intensities of the incident and attenuated gamma rays, respectively, and tenotes the mass thickness of the sample.)

and the mass attenuation coefficient (MAC) is calculated by dividing the LAC by the specific gravity of the material. The MAC gives the rate of attenuation of the beam per unit mass and is expressed as [36-38];

$\mu_{m}=\frac{\mu}{\rho}$

(where $\mu$ shows the linear attenuation coefficient (expressed in $\mathrm{cm}^{-1}$ ) defines a measure of the possibility of photon interaction when radiation passes through a target material, depending on the thickness of the material, where $\mu \mathrm{m}$ shows mass attenuation coefficient, and $\rho$ shows the density of the material.)

The appropriate material thickness that causes the intensity of radiation passing through a target to decrease to half intensity by interacting with the material is also called the half-value layer (HVL) and is expressed with the formula [36-38];

$H V L=\frac{\operatorname{In} 2}{\mu}$

The tenth-value layer (TVL) is defined as the material depth value that allows the incoming radiation intensity to decrease to one-tenth value and is formulated in the form of [36-38];

$T V L=\frac{\operatorname{In} 10}{\mu}$

The mean free path (MFP), another of the shielding parameters, is defined by the following formula as the distance traveled by a particle before possible collisions with other particles [36-38].

$m f p=\frac{1}{\mu}$

The effective atomic number $\left(\mathrm{Z}_{\mathrm{eff}}\right)$ is a parameter that has any real constant value for a given material, which gives the common behavior of electrons in the interaction of materials with radiation [36-38].

$Z_{e f f}=\frac{\sum_{i} f_{i} A_{i}\left(\mu_{\rho}\right)_{i}}{\sum_{j} f_{j} \bar{A}_{j}}$

Also, there is a linear relationship between the effective atomic number $\left(\mathrm{N}_{\text {eff }}\right)$ and the electron density defined by the following expression [3031].
$N_{e f f}=N_{A} \frac{Z_{e f f}}{\left.<A_{e f f}\right\rangle}$ (electrons $\left./ \mathrm{g}\right)$

(where $\mathrm{N}_{\mathrm{A}}$ is Avogadro constant and $\mathrm{A}_{\mathrm{eff}}$ is the effective atomic mass value, also known as the ratio of atomic weight to total atomic number [36-38].)

The buildup factor is a factor that includes the response of non-colliding photons to add the participation of scattered photons. Exposure Buildup factor (EBF) is a parameter related to the amount of absorption or stored energy in the air, and this parameter determines the extent of the interaction that may occur in the air, between the source and the detector. Energy absorption build up factor $(\mathrm{EABF})$ is a parameter related to the amount of energy absorbed in the substance with which the radiation interacts in different substances [36-45].

\subsection{Py-MLBUF}

To investigate the gamma-ray shielding parameters of the materials, a thorough understanding of the various gamma-ray shielding parameters (GSP) is needed. By measuring gamma-ray shielding parameters, the computer plays an important role in this form of study. [46]. The storage and processing of useful radioactive materials in radiology establishments has become a critical issue as nuclear technology and safety requirements have advanced. A gamma-ray shielding enclosure (GSE) must be designed with suitable materials to protect the environment from harmful self-emitting ionizing radiations from radioactive materials. Shielding is one of the most effective ways to reduce the harmful effects of ionizing radiation on living tissues. Shield designers should investigate the suitability of materials using gamma-ray shielding parameters to choose a suitable material for the GSE. Py-MLBUF is the name of the platform's computer code, which is written in Python and calculates gamma-ray shielding parameters in the energy range of $0.015-$ $15 \mathrm{MeV}$ [47-49].

Table 1. The weight fractions and theoretical densities of $5 \mathrm{~B}_{2} \mathrm{O}_{3}-40 \mathrm{SiO}_{2}-(55-x) \mathrm{Al}_{2} \mathrm{O}_{3}-x \mathrm{BaO}(x=25,28,31$ and 34)

\begin{tabular}{|c|c|c|c|c|c|c|}
$\begin{array}{c}\text { Sample } \\
\text { Code }\end{array}$ & $\mathbf{B}$ & $\mathbf{S i}$ & $\mathbf{A l}$ & $\mathbf{B a}$ & $\mathbf{O}$ & $\begin{array}{c}\text { Density } \\
\left(\mathbf{g} / \mathbf{c m}^{\mathbf{3}}\right)\end{array}$ \\
\hline BSABa25 & 0.016 & 0.187 & 0.159 & 0.224 & 0.415 & 3.798 \\
\hline BSABa28 & 0.016 & 0.187 & 0.143 & 0.251 & 0.404 & 3.851 \\
\hline BSABa31 & 0.016 & 0.187 & 0.127 & 0.278 & 0.393 & 3.904 \\
\hline BSABa34 & 0.016 & 0.187 & 0.111 & 0.305 & 0.382 & 3.957 \\
\hline
\end{tabular}



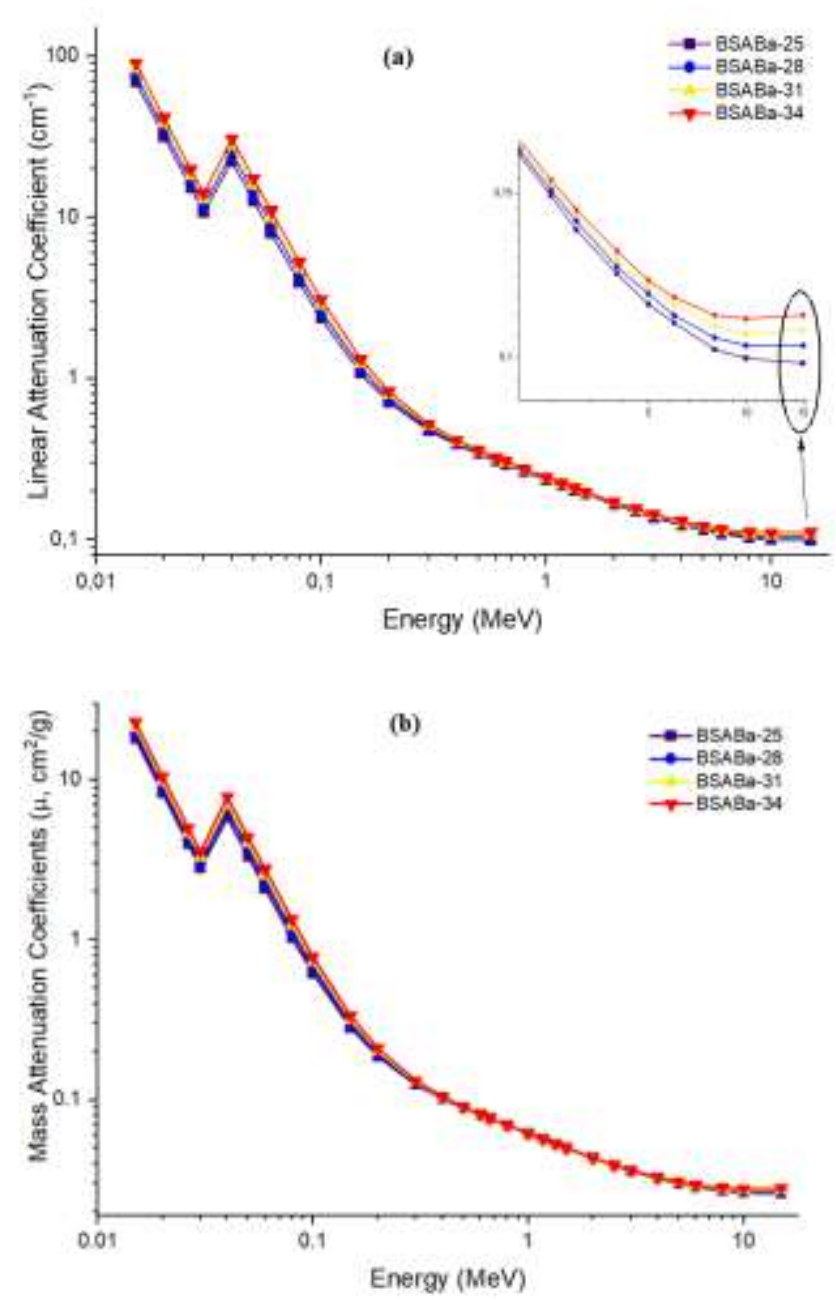

Figure 1. (a) Variation of linear attenuation coefficients (LAC) (b) mass attenuation coefficients (MAC) versus photon energy for BSBa-x $(x=25,28,31$ and 34) glasses.

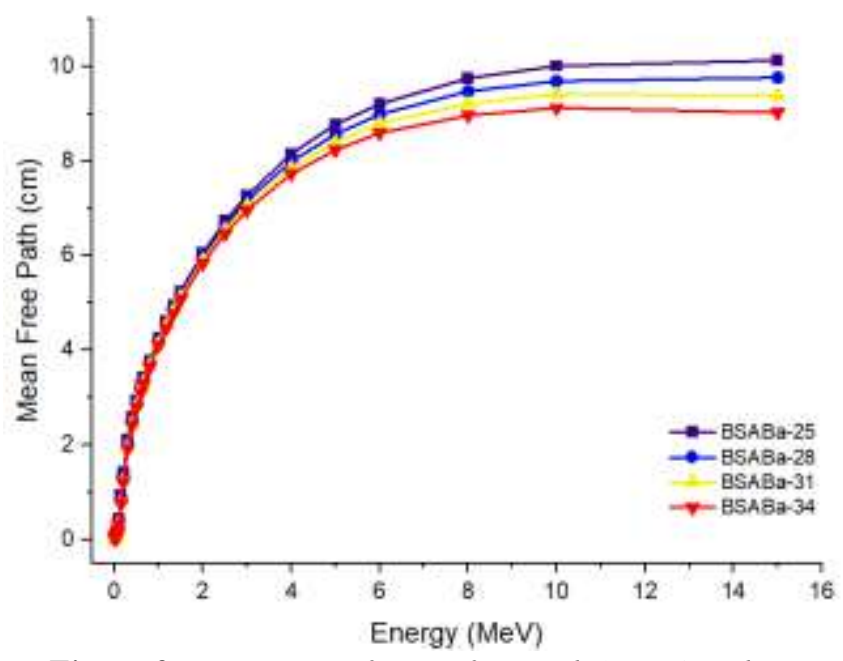

Figure 2. Variations of mean free path $(M F P)$ with photon energy for for BSBa-x $(x=25,28,31,34)$ glasses.

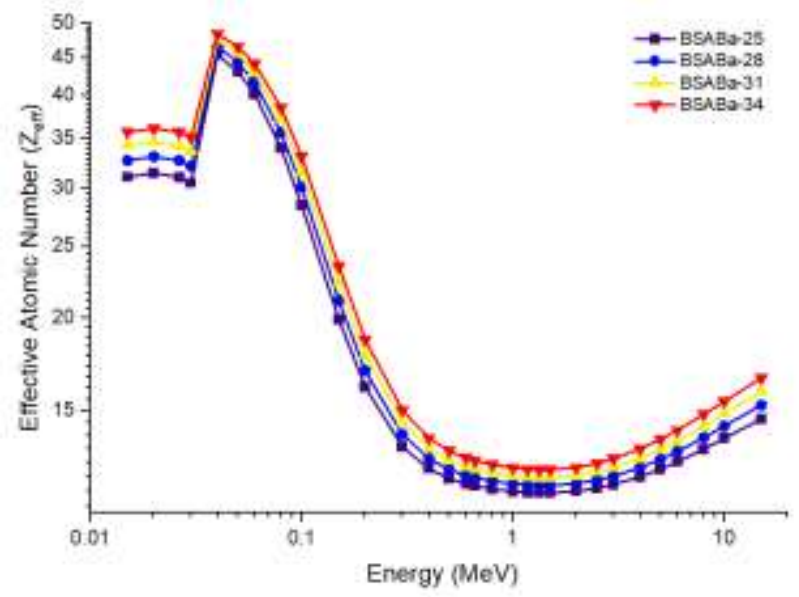

Figure 3. Effective atomic number $\left(Z_{\text {eff }}\right)$ with photon energy for BSBa-x (x=25, 28, 31 and 34) glasses.

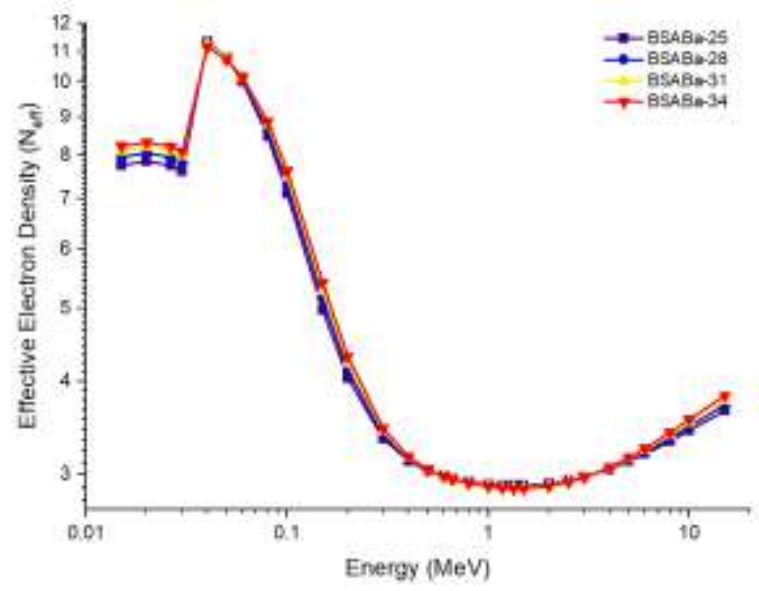

Figure 4. Effective electron density $\left(N_{\text {eff }}\right)$ with photon energy for energy for BSBa-x ( $x=25,28,31$ and 34) glasses.

\section{Results and Discussion}

Table 1 shows theoretical density, which range from 3.798 to $3.957 \mathrm{~g} / \mathrm{cm}^{3}$, and weight fractions of each glasses. The samples with the lowest density are BSABa-25. When density is examined in general, increase in concentration of $\mathrm{BaO}$ is found to have a major effect on the density of BSABa-X glasses. As can be seen in Figure 1, when the density increases LAC $(\mu)$ values, which are determined between $0.015-15 \mathrm{MeV}$ photon energy range (Fig. 1 (a)), and MAC (Fig. 1 (b)) values are getting higher value than those with low density. To begin with, we can see that the LAC has distinct behavior in three different photon energy zones. In the collision phase, the photoelectric effect becomes more dominant (at $0.04 \mathrm{MeV}$ ) as LAC values decrease and gamma energy increases in the low energy field. The decay rates slowed as the energy level increased. 

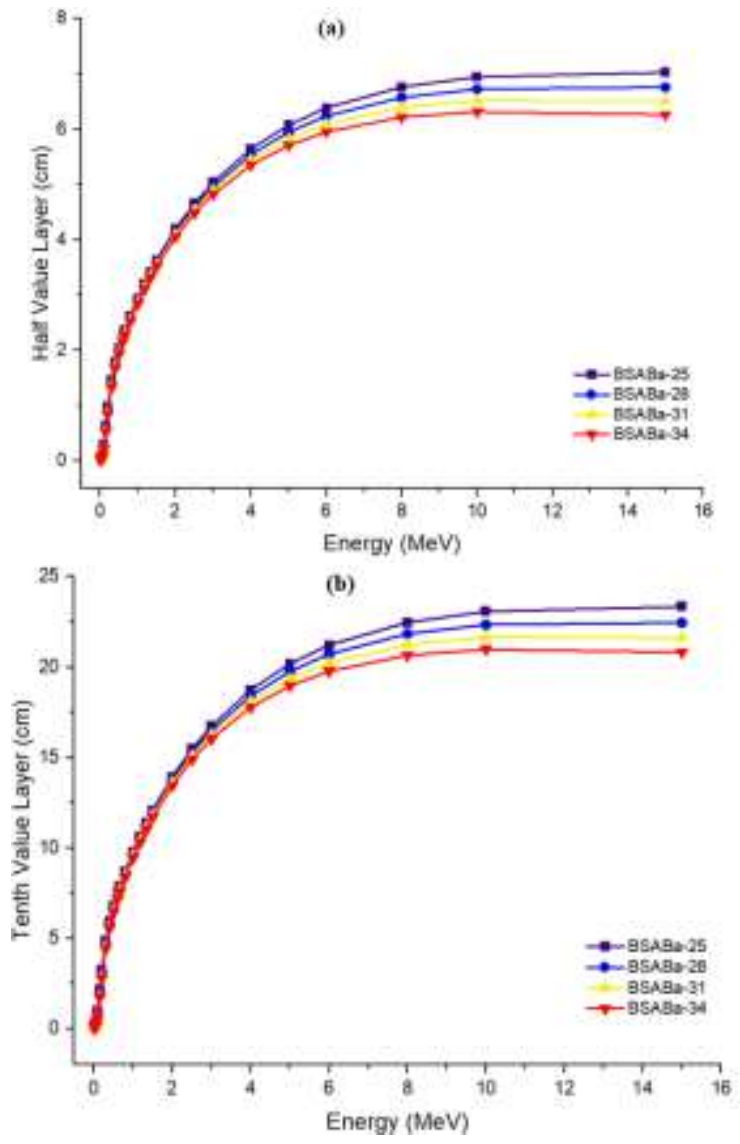

Figure 5. (a) Variation of half-value layer (HVL) (b) tenth-value layer (TVL) versus photon energy for BSBa-x $(x=25,28,31$ and 34) glasses.

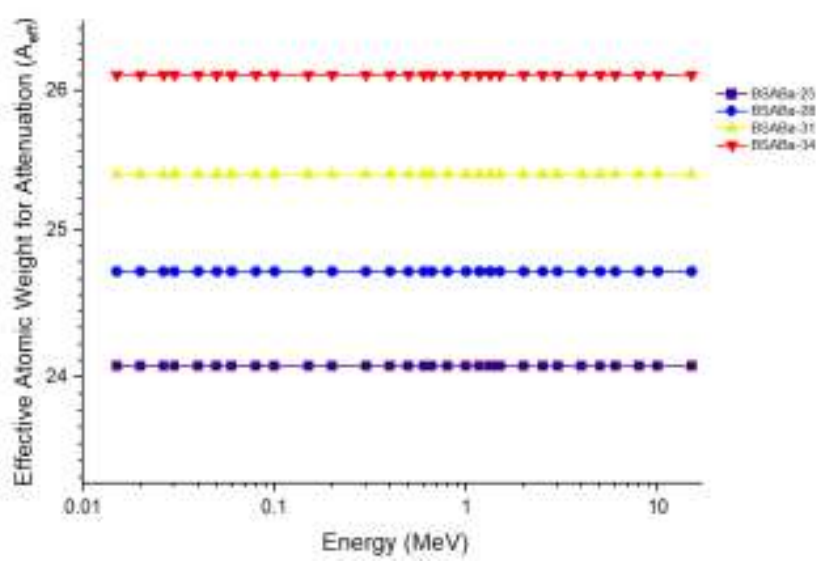

Figure 6. Effective atomic weight for attenuation $\left(A_{\text {eff }}\right)$ with photon energy for for BSBa-x $(x=25,28,31$ and 34) glasses.

According to our findings, the maximum LAC values for the BSABa-34 sample are observed at the investigated photon energies. The chemical structure and theoretichal density value of the BSABa-34 sample may clarify the situation. Where the density of BSABa-25 is $3.798 \mathrm{~g} / \mathrm{cm}^{3}$ in the BSABa-34 and $3.957 \mathrm{~g} / \mathrm{cm}^{3}$ in the BSABa-34 sample.
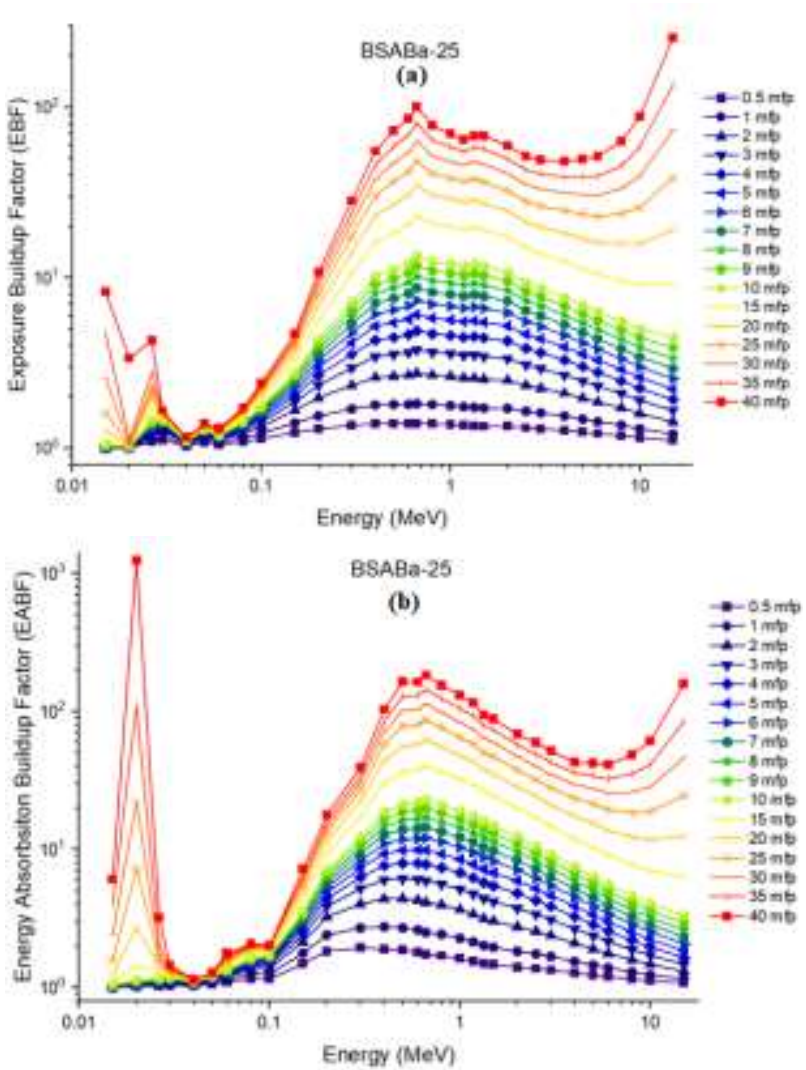

Figure 7. (a) Variations of exposure buildup factor $(E B F)(b)$ energy absorption buildup factor $(E A B F)$ with photon energy at different mean free paths for BSABa-25 glass system.
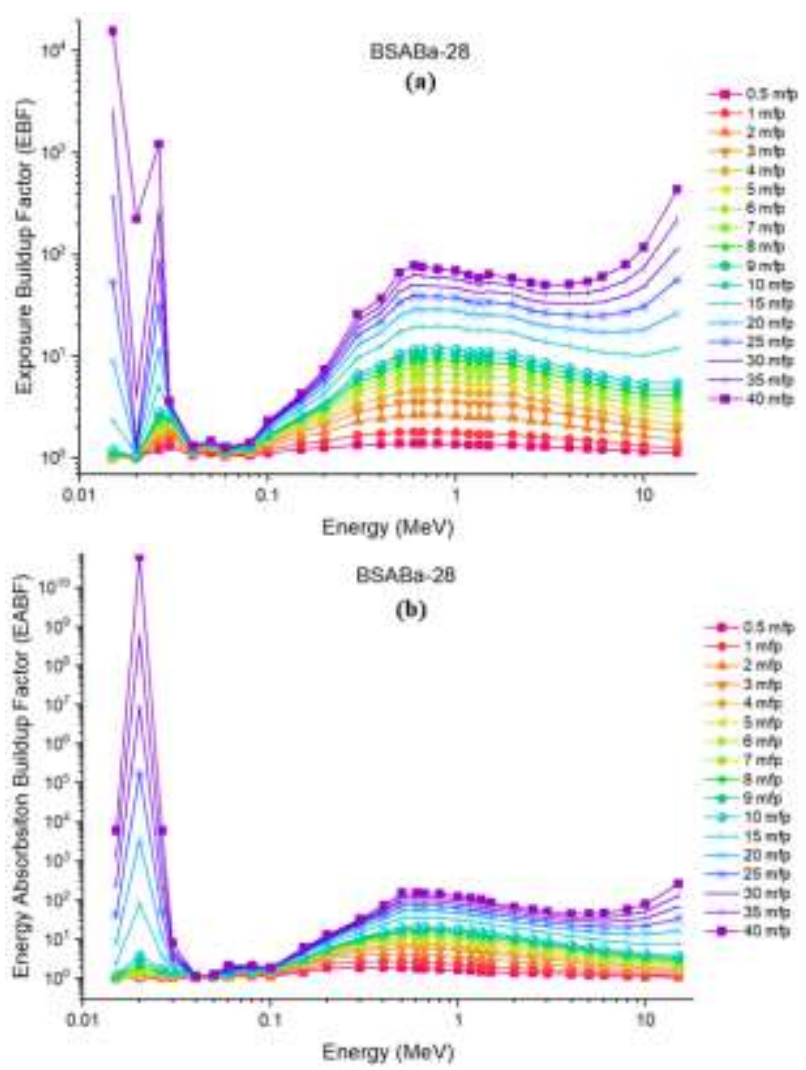

Figure 8. (a) Variations of exposure buildup factor $(E B F)(b)$ energy absorption buildup factor $(E A B F)$ with photon energy at different mean free paths for BSABa-28 glass system. 



Figure 9. (a) Variations of exposure buildup factor $(E B F)(b)$ energy absorption buildup factor $(E A B F)$ with photon energy at different mean free paths for BSABa-31 glass system.
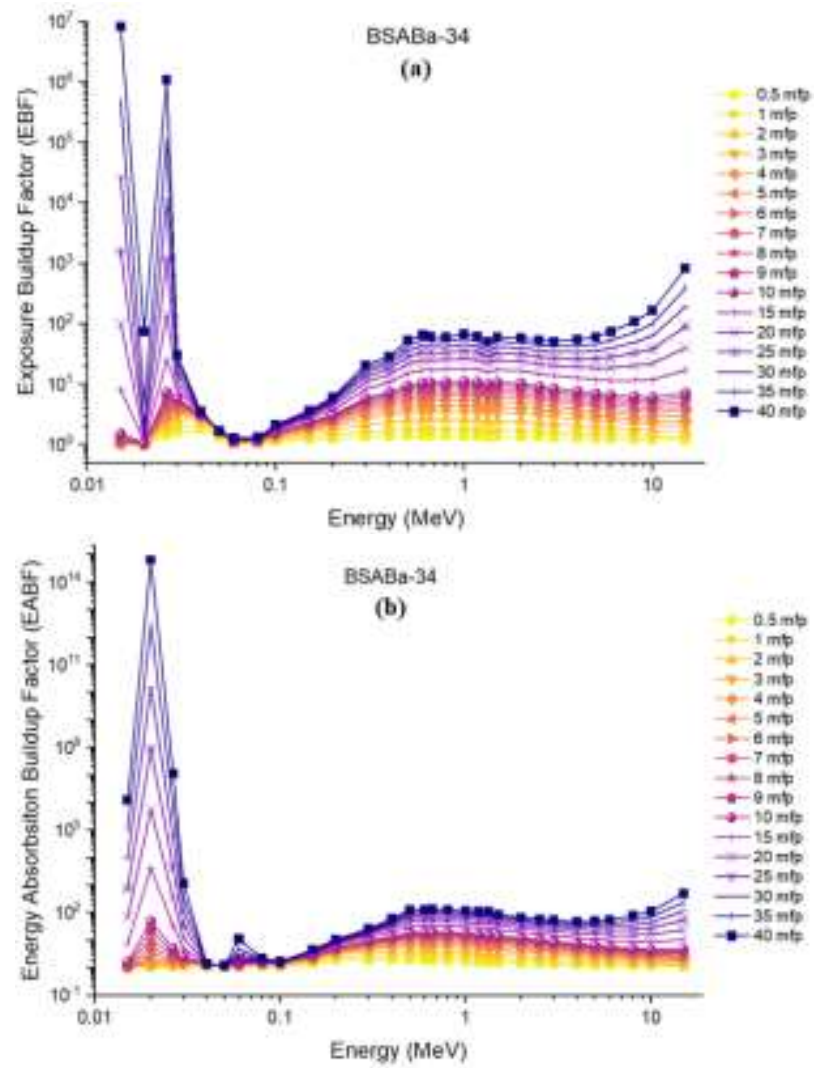

Figure 10. (a) Variations of exposure buildup factor $(E B F)(b)$ energy absorption buildup factor $(E A B F)$ with photon energy at different mean free paths for BSABa-34 glass system.

As a result, the aforementioned substitution results in a noticeable increase in LAC values. For BSABa-25, BSABa-28, BSABa-31, and BSABa-34 samples at $0.015 \mathrm{MeV}$, LAC values are stated as $69.000,76.000,83.100$ and $90.400 \mathrm{~cm}^{-1}$, respectively. Furthermore, LAC values at $15 \mathrm{MeV}$ (highest energy of recent investigation) are stated as $0.099,0.103,0.107$ and 0.111 , respectively. The increase in $\mathrm{BaO}$ content in glass samples from $25 \%$ to $34 \%$ resulted in a rigid increase in density.

The mean free path (MFP) is also a determining factor for a material's gamma shielding abilities. Figure 2 shows a graphical representation of the MFP values for four different types of glass. At various gamma ray energies, the lowest measured MFP values for the BSABa-34 sample are also reported.

In terms of gamma ray attenuation properties, the effective atomic number $\left(Z_{\text {eff }}\right)$ is a useful term for evaluating the material's suitability for gamma-ray applications, and it is related to the partial photon mitigation process. Figure 3 shows the $\left(\mathrm{Z}_{\mathrm{eff}}\right)$ of the investigated glass samples as a function of photon energy. According to the results, the maximum $\mathrm{Z}_{\mathrm{eff}}$ for the BSABa-34 glass sample is reported as 48.392 for $0.04 \mathrm{MeV}$. Other BSABa-x samples have been shown to be in similar situations. $Z_{\text {eff }}$ BSABa-34 > BSABa-31 > BSABa-28 > BSABa-25 is the overall order of Zeff. In terms of $\mathrm{N}_{\text {eff }}$ values for BSABa-x glass samples, there is also a linear relationship between the effective atomic number $\left(\mathrm{N}_{\text {eff }}\right)$, as shown in Figure 4, with Neff-BSABa-34 > BSABa-31 > BSABa-28 > Zeff-BSABa-25 as the overall order of $\mathrm{N}_{\mathrm{eff}}$.

Investigated glasses are also tested in terms of the HVL. The term HVL is a crucial parameter for determining the thickness of shielding material needed to reduce the initial intensity by half $(50 \%)$. As a result, this parameter can be used for future glass shield applications that take into account the physical environment and the suitability of shielding material placement in a given region. Figure 5 (a) illustrates the changes in the half value layer (HVL) values of the glass samples against to incident photon energy. The HVL values of glass samples increase as the incident photon energy increases. From 0.015 to $5 \mathrm{MeV}$, a rigid increment is registered. The average maximum HVL values for all glass samples are reported as 6.075, 5.949, 5.826 and $5.708 \mathrm{~cm}$ at $5 \mathrm{MeV}$ photon energy for BSABa-25, BSABa-28, BSABa-31 and BSABa-34 
samples, respectively. It can be seen that, HVL difference between BSABa-25 and BSABa-34 sample is $0.367 \mathrm{~cm}$ at $5 \mathrm{MeV}$. It means that $\mathrm{BaO}$ additive from 25 to $34 \%$ decreased the required shielding thickness as $0.367 \mathrm{~cm}$ for $5 \mathrm{MeV}$ gamma rays. Similarly, the lowest HVL values are observed for BSABa-34 sample at all energies. This is another indicator for superior shielding properties of BSABa-34 sample against ionizing gamma rays. A similar pattern can be seen in Figure 5 (b), which shows the HVL values, which are the material depth values that enable the intensity of incoming radiation to be reduced to one-tenth of its original value. Besides, the MFP value (Figure 2) is clearly on a downward slope, similar to the HVL value.

The effective atomic weight $\left(\mathrm{A}_{\text {eff }}\right)$, which is known as the ratio of atomic weight to total atomic number, reaches its maximum value for BSABa-34 glass sample as seen in Figure 6. As the $\mathrm{BaO}$ concentration rises, the effective atomic weight value rises as well, indicating that the BSABa-34 glass becomes more radiation resistant.

The buildup factor is a correction factor for the effect of scattered radiation in the presence of secondary particles in the medium. The accumulation causes of secondary ionizing radiation must be considered when accounting for secondary ionizing radiation accumulation. As a result, the factor of accumulation is a multiplier that makes up for the reaction to non-confronted photons in order to integrate the contribution of scattered photons. The multiplier in the buildup portion absorbs non-confronted photons, allowing the contribution of scattered photons to be included. Exposure buildup factor (EBF) and energy absorption buildup factor (EABF) are two subcategories of the principle of buildup factor (EABF). The Py-MLBUF is used to measure the terms of EBF and EABF values for four BSABa-x separate glasses between 0.5 and $40 \mathrm{mfp}$. Figure 710 (a) describes the relationship between exposure buildup factor (EBF) and energy for various $\mathrm{mfp}$ values. Different chemical reactions take place in various natural settings. The first region shown peaked because the atomic number is close to the binding energy of the elements with the highest atomic numbers. As a consequence, in the Compton resonance region, the EBF values are nearly constant. The third field of interest is pair production, where there is a small rise in EBF due to absorption processes. The EBF value of the BSABa-34 sample is found to be the lowest. This is an excellent example of how well materials can shield gamma rays. As a consequence, among the investigated specimens, the best extracted sample is BSABa-34, which has the lowest EBF values. In the energy absorption buildup factor (EABF) is plotted against photon energy (MeV) from 5 to 40 $\mathrm{mfp}$ and a similar pattern can be seen. in Figure 710 (b).

\section{Conclusions}

In terms of radiation shielding parameters, we investigated $5 \mathrm{~B}_{2} \mathrm{O}_{3}-40 \mathrm{SiO}_{2}-(55-x) \mathrm{Al}_{2} \mathrm{O}_{3}-x \mathrm{BaO}$ (BSABa-x) glass systems (where $\mathrm{x}=25,28,31$ and 34) and determined their radiation resistance properties. The glass density increased from 3.798 $\mathrm{g} / \mathrm{cm}^{3}$ to $3.957 \mathrm{~g} / \mathrm{cm}^{3}$ when the $\mathrm{BaO}$ concentration is increased linearly (i.e. 25, 28, 31 and $34 \%$ mole). On the other hand, from 25 to 34 mole percent $\mathrm{BaO}$ reinforcement, a total increase of $0.159 \mathrm{~g} / \mathrm{cm}^{3}$ is given (i.e. between BSABa-25 and BSABa-34). As a result, we would like to emphasize that a direct $34 \%$ mole substitution of $\mathrm{BaO}$ results in a net density difference of $0.159 \mathrm{~g} / \mathrm{cm}^{3}$. The hypothesis that the radiation resistance of glass will increase as $\mathrm{BaO}$ density increases is clearly validated by the results, and it can be stated that $\mathrm{BaO}$ has a clear effect on the radiation attenuation qualities. It can be concluded that $\mathrm{BaO}$ has a clear effect on the attenuation properties of radiation. The BSABa-34 with the highest $\mathrm{BaO}$ additive exhibits the greatest attenuation of photons, indicating that $\mathrm{BaO}$ reinforcement has strong anti-nuclear radiation resistance properties. Finally, in light of the scientific community's ongoing efforts on the promising lead-free barium and aluminum oxide added to borosilicate glass system, we would like to propose some potential future investigations.

\section{Author Statements:}

- The authors declare that they have equal right on this paper.

- The authors declare that they have no known competing financial interests or personal relationships that could have appeared to influence the work reported in this paper

- The authors declare that they have nobody or nocompany to acknowledge.

\section{References}

[1] A.S. Abouhaswa, H.O. Tekin, E. Kavaz, U. Perisanoglu. Optical and nuclear radiation protection characteristics of lithium bismo-borate glasses: Role of $\mathrm{ZrO}_{2}$ substitution. Radiation Physics and Chemistry, 
2021.https://doi.org/10.1016/j.radphyschem.2021. 109428.

[2] H.O.Tekin, L.R.P. Kassab, Shams A.M. Issa, C.D.S. Bordon, E.E. Altunsoy Guclu, G.R. da Silva Mattos, O. Kilicoglu. Synthesis and nuclear radiation shielding characterization of newly developed germanium oxide and bismuth oxide glasses. Ceramic International, 2019. https://doi.org/10.1016/j.ceramint.2019.08.204.

[3] Singh J, Singh H, Sharma J, Singh T, Singh PS. Fusible alloys: a potential candidate for gamma rays shield design. Prog. Nucl. Energy, 2018. https://doi.org/10.1016/j.pnucene.2018.04.002.

[4] Kaewkhao J., Pokaipisit A., Limsuwan P. Study on borate glass system containing with $\mathrm{Bi}_{2} \mathrm{O}_{3}$ and $\mathrm{BaO}$ for gamma-rays shielding materials: Comparison with $\mathrm{PbO}$. Journal of Nuclear Materials $\quad 2010 ; \quad 399$ : 38-40. https://doi.org/10.1016/j.jnucmat.2009.12.020.

[5] Sodhi K.S., Krishna S., Saxena A.K., Sinha A., Khandelwal N., Lee E.Y. Clinical application of "Justification" and "Optimization" principle of ALARA in pediatric CT imaging:'how many children can be protected from unnecessary radiation?'. Europ. Jour. Rad. 2015. https://doi.org/10.1016/j.ejrad.2015.05.030.

[6] S.A.M. Issa. Effective atomic number and mass attenuation coefficient of $\mathrm{PbO}-\mathrm{BaO}-\mathrm{B}_{2} \mathrm{O}_{3}$ glass system.

Radiat.Phys.Chem., 2016. https://doi.org/10.1016/ j.radphyschem.2015.11.025.

[7] N. Singh, K.J. Singh, K. Singh, H. Singh. Comparative study of lead borate and bismuth lead borate glass systems as gamma-radiation shielding materials. Nucl. Instrum. Meth. Phys. Res. B 225 (2004)

305-309.

https://doi.org/10.1016/j.nimb.2004.05.016

[8] Ab Latif Wani, Anjum Ara, Jawed Ahmad Usmani. Lead toxicity: a review. Interdisiplinary toxicology, 2015. https://doi.org/10.1515/intox2015-0009.

[9] Monisha Ja1shankar, Tenzin Tseten, Naresh Anbalagan, Blessy B. Mathew, Krishnamurthy N. Beeregowda. Toxicity, mechanism and health effects of some heavy metals. Interdisiplinary toxicology, 2014. https://doi.org/10.2478/intox2014-0009.

[10] Y.Al-Hadeethi, S.A.Tijani. The use of lead-free transparent $50 \mathrm{BaO}-(50-\mathrm{x})$ borosilicate $-\mathrm{xBi}_{2} \mathrm{O}_{3}$ glass system as radiation shields in nuclear medicine. Journal of Alloys and Compounds, 2019.

https://doi.org/10.1016/j.jallcom.2019.06.259.
[11] H.O. Tekin, O. Kilicoglu. The influence of gallium (Ga) additive on nuclear radiation shielding effectiveness of $\mathrm{Pd} / \mathrm{Mn}$ binary alloys. Journal of Alloys and Comp., 2019. https://doi.org/10.1016/j.jallcom.2019.152484.

[12] Ersundu A.E., Buyukyildiz M., Celikbilek Ersundu M., Sakar E., Kurudirek M. The heavy metal oxide glasses within the $\mathrm{WO}_{3}-\mathrm{MoO}_{3}-\mathrm{TeO}_{2}$ system to investigate the shielding properties of radiation applications. Progress in Nuclear Energy, 2018. https://doi.org/10.1016/j.pnucene.2017.10.008.

[13] P.A. Meyer, M.J. Brown, H. Falk. Global approach to reducing lead exposure and poisoning Mutat. Res.

Rev.Mutat.Res., 2008. https://doi.org/10.1016/j.mrrev.2008.03.003.

[14] K.A. Fetterly, D.J. Magnuson, G.M. Tannahill, M.D. Hindal, V. Mathew. Effective use of radiation shields to minimize operator dose during invasive cardiologyprocedures. JACC Cardiovasc. Interv.,

2011. https://doi.org/10.1016/j.jcin.2011.05.027.

[15] Tijani S.A., Kamal S.M., Al-Hadeethi Y., Arib M. Hussein M.A., Wageh S., et al. Radiation shielding properties of transparent erbium zinc tellurite glass system determined at medical diagnostic energies. $\mathrm{J}$.
Alloy
Comp.,
2018 .

https://doi.org/10.1016/jjallcom.2018.01.109.

[16] M.A.M.Uosif, A.M.A. Mostafa Shams A.M.Issa, H.O.Tekin, Z.A. Alrowaili, O.Kilicoglu. Structural, mechanical and radiation shielding properties of newly developed tungsten lithium borate glasses: an experimental study. Journal of Non-Crystalline Solids, 2020. https://doi.org/10.1016/j.jnoncrysol.2019.119882.

[17] E.Kavaz, H.O.Tekin, G.Kilic, G.Susoy. Newly developed Zinc-Tellurite glass system: An experimental investigation on impact of $\mathrm{Ta}_{2} \mathrm{O}_{5}$ on nuclear radiation shielding ability. Journal of NonCrystalline Solids, 2020. https://doi.org/10.1016/j.jnoncrysol.2020.120169.

[18] H.A.Saudi, H.O.Tekin, Hesham M.H. Zakalyde Shams, A.M.Issa, G.Susoy, M.Zhukovsky. The impact of samarium (III) oxide on structural, optical and radiation shielding properties of thallium-borate glasses: Experimental and numerical investigation. Optical Materials, 2021. https://doi.org/10.1016/j.optmat.2021.110948.

[19] G. Kilic, S. Issa, E. İlik, O. Kilicoglu, H.O. Tekin. A journey for exploration of Eu2O3 reinforcement effect on zinc-borate glasses: Synthesis, optical, physical and nuclear radiation shielding properties. Ceramics International, 2021 https://doi.org/10.1016/j.ceramint.2020.09.103. 
[20] El-Sayed A. Waly, Michael A. Fusco, Mohamed A. Bourham. Gamma-ray mass attenuation coefficient and half value layer factor of some oxide glass shielding materials. Ann. Nucl. Energy, 2016.

https://doi.org/10.1016/j.anucene.2016.05.028.

[21] R. Wu, J.D. Myers, M.J. Myers. New generation high-power rare-earth-doped phosphate glass fiber and fiber laser Proc SPIE - Solid State Lasers X, 4267 (2001), pp. 56-60. ISBN: 1-55752-661-3. https://www.osapublishing.org/abstract.cfm?URI= ASSL-2001-MB2.

[22] J. Hubbell. Photon mass attenuation and energyabsorption coefficients Int $\mathbf{J}$ Appl Radiat Isot, 1982. https://doi.org/10.1016/0020708X(82)90248-4.

[23]G. Susoy, E.E.A. Guclu, O. Kilicoglu, M. Kamislio glu, M.S. Al-Buriahi, M.M. Abuzaid, H.O. Tekin. The impact of $\mathrm{Cr}_{2} \mathrm{O}_{3}$ additive on nuclear radiation shielding properties of $\mathrm{LiF}-\mathrm{SrO}-\mathrm{B}_{2} \mathrm{O}_{3}$ glass system. Materials Chemistry and Physics, 2020. https://doi.org/10.1016/j.matchemphys.2019.12248 1.

[24] C. Jayachandran. Calculated effective atomic number and kerma values for tissue-equivalent and dosimetry materials Phys Med Biol, 16 (4) (1971), p. $617 . \quad$ https://doi.org/10.1088/00319155/16/4/005.

[25]M. Taylor, R. Franich, J. Trapp, P. Johnston. Electron interaction with gel dosimeters: effective atomic numbers for collisional, radiative and total interaction processes Radiat Res, 171 (1) (2009), pp. 123-126. doi: 10.1667/RR1438.1.

[26] Mohammad W. Marashdeh, Ibrahim F. AlHamarneh, Eid M. Abdel Munem, , A. A. Tajuddin, A. Ariffin, Saleh Al-Omari. Determining the mass attenuation coefficient, effective atomic number, and electron density of raw wood and binderless particleboards of Rhizophora spp. by using Monte Carlo simulation, Results in Physics, 2015. https://doi.org/10.1016/j.rinp.2015.08.009.

[27] Kulwinder Singh Mann, Sukhmanjit Singh Mann. Py-MLBUF: Development of an online-platform for gamma-ray shielding calculations and investigations. Annals of Nuclear Energy, 2021. https://doi.org/10.1016/j.anucene.2020.107845.

[28]S.Kaewjaeng, J.Kaewkhao, P.Limsuwan, U.Maghanemi. Effect of $\mathrm{BaO}$ on Optical, Physical and Radiation Shielding Properties of $\mathrm{SiO}_{2}-\mathrm{B}_{2} \mathrm{O}_{3}-$ $\mathrm{Al}_{2} \mathrm{O}_{3}-\mathrm{CaO}-\mathrm{Na}_{2} \mathrm{O}$ Glasses System. Procedia Engineering, 2012. https://doi.org/10.1016/j.proeng.2012.02.058.

[29] Singh K., Singh H., Sharma V., Nathuram R., Khanna A., Kumar R., Bharri S.S., Sahora H.S.
Gamma-ray attenuation coefficient in bismuth borate glass, Journal of Nuclear Instruments and Methods in Physics Research 2002; 194:1-6. http://dx.doi.org/10.4236/jep.2016.72023.

[30] Sing S., Kumar A., Sing D., Thind K.S. Barium-borate-flyash-glasses: As radiation shielding materials, Journal of Nuclear Instruments and Methods in Physics Research, 2008; 206:140-146. https://doi.org/10.1016/j.nimb.2007.10.018.

[31] E.Kavaz, F.I.El Agawany, H.O.Tekin, U.Perisanoglu, Y.S.Rammah. Nuclear radiation shielding using barium borosilicate glass ceramics, 2020. https://doi.org/10.1016/j.jpcs.2020.109437.

[32] U. Kara, S.A.M. Issa, G. Susoy, M Rashad, E. Kavaz, N.Y. Yorgun, H.O.Tekin. Synergistic effect of serpentine mineral on $\mathrm{Li}_{2} \mathrm{~B}_{4} \mathrm{O}_{7}$ glasses: optical, structural and nuclear radiation shielding properties. Applied Physics A, 2020 https://doi.org/10.1016/j.jnoncrysol.2020.120049.

[33] H.O. Tekin, Shams A.M. Issa, E. Kavaz. The direct effect of $\mathrm{Er}_{2} \mathrm{O}_{3}$ on bismuth barium telluro borate glasses for nuclear security applications. Mater.

Res. Express., 2019. https://doi.org/10.1088/2053$1591 / \mathrm{ab} 4 \mathrm{cb} 5$.

[34] M.M. Abuzaid, G. Susoy, S.A.M. Issa, W. Elshami, O. Kilicoglu, H.O. Tekin. Relationship between melting-conditions and gamma shielding performance of fluoro-sulfo-phosphate (FPS) glass systems: a comparative investigation. Ceramics International,

2020. https://doi.org/10.1016/j.ceramint.2020.03.065.

[35] O. Kilicoglu, H.O. Tekin. Bioactive glasses and direct effect of increased $\mathrm{K}_{2} \mathrm{O}$ additive for nuclear shielding performance: a comparative investigation. Ceramics International, 2020 https://doi.org/10.1016/j.ceramint.2019.09.095.

[36]U. Kara, E. Kavaz, ShamsA.M.Issa, M. Rashad, G. Susoy, A.M.A. Mostafa, N. Yildiz

Yorgun, H.O. Tekin. Optical, structural and nuclear radiation shielding properties of $\mathrm{Li}_{2} \mathrm{~B}_{4} \mathrm{O}_{7}$ glasses: efect of boron mineral additive. Applied Physics A, 126 (2020), p. 261. https://doi.org/10.1007/s00339-020-3397-8.

[37] H.O. Tekin, V.P. Singh, T. Manici. Effects of micro-sized and nano-sized $\mathrm{WO}_{3}$ on mass attenauation coefficients of concrete by using MCNPX code Appl. Radiat. Isot., 2017. https://doi.org/10.1016/j.apradiso.2016.12.040.

[38] M.M. Hosamani, N.M. Badiger Determination of effective atomic number of composite materials using backscattered gamma photons - a novel 
method Chem Phys. Lett, 2018 https://doi.org/10.1016/j.cplett.2018.02.012.

[39] Perisanoglu U., Kavaz E., Tekin H.O., Armoosh S.R., Ekinci N., Oltulu M. Comparison of gamma and neutron shielding competences of $\mathrm{Fe}-\mathrm{Cu}$ - and brassadded Portland cement pastes: an experimental and Monte Carlo study. Appl. Phys. A Mater. Sci. Process., 2020. https://doi.org/10.1007/s00339-020-03648-6.

[40] Saddeek Y.B., Issa S.A.M., Guclu E.E.A., Kilicoglu O., Susoy G., Tekin H.O. Alkaline phosphate glasses and synergistic impact of germanium oxide (GeO2) additive: mechanical and nuclear radiation shielding behaviors.Ceram.Int., 2020. https://doi.org/10.1016/j.ceramint.2020.03.254.

[41] Tekin H.O. MCNP-X Monte Carlo code application for mass attenuation coefficients of concrete at different energies by modeling $3 \times 3$ inch $\mathrm{NaI}(\mathrm{Tl})$ detector and comparison with XCOM and Monte Carlo data. Sci. Technol.Nucl.Install., 2016. https://doi.org/10.1155/2016/6547318, 2016.

[42] Alatawi A., Alsharari A.M., Issa S.A.M., Rashad M., Darwish A.A.A., Saddeek Y.B., Tekin H.O. Improvement of mechanical properties and radiation shielding performance of $\mathrm{AlBiBO}_{3}$ glasses using yttria: an experimental investigation. Ceram. Int. 2020.

https://doi.org/10.1016/j.ceramint.2019.10.069.

[43] Issa Shams A.M., Susoy G., Ali A.M., Tekin H.O., Saddeek Y.B., Al-Hajry A., Algarni H., Anjana P.S., Agar O. The effective role of $\mathrm{La} 2 \mathrm{O} 3$ contribution

on zinc borate glasses: radiation shielding and mechanical properties. Appl. Phys. A Mater. Sci. $\quad 2019$. https://doi.org/10.1007/s00339-019-3169-5.

[44] Kara U., Issa S.A.M., Yorgun N.Y., Kilicoglu O., Rashad M., Abuzaid M.M., Kavaz E., Tekin H.O. Optical, structural and gamma ray shielding properties of dolomite doped lithium borate glasses for radiation shielding applications. J. NonCryst. Solids, 2020. https://doi.org/10.1016/j.jnoncrysol.2020.120049.

[45] Kavaz E., Ekinci N. A study of energy absorption and exposure buildup factors in medicinal samples. Asian J. $\quad$ Chem., 2016. .https://doi.org/10.14233/ajchem.2016.19740.

[46] M.L. Taylor, R.L. Smith, F. Dossing, R.D. Franich. Robust calculation of effective atomic numbers: the Auto- $Z_{\text {eff }}$ software Med Phys, 2012. https://doi.org/10.1118/1.3689810.
[47] S. Gowda, S. Krishnaveni, R. Gowda. Studies on effective atomic numbers and electron densities in amino acids and sugars in the energy range 30$1333 \mathrm{keV}$. Nucl Instrum Methods B, 2005. https://doi.org/10.1016/j.nimb.2005.05.048.

[48] M.F. Kaplan Concrete radiation shielding John Wiley \& Sons Inc, New York (1989). ISBN 0-47021338-8.

[49] B. Alim, Determination of Radiation Protection Features of the $\mathrm{Ag}_{2} \mathrm{O}$ Doped Boro-Tellurite Glasses Using Phy-X / PSD Software, Journal of the Institute of Science and Technology, 2020. https://doi.org/10.21597/jist.640027. 